Article

\title{
Cytokinesis D is Mediated by Cortical Flow of Dividing Cells Instead of Chemotaxis
}

\author{
Yuki Tanaka ${ }^{1}$, Md. Golam Sarowar Jahan ${ }^{1,2}$, Tomo Kondo ${ }^{1,3}{ }^{\circledR}$, Masaki Nakano ${ }^{1}$ and \\ Shigehiko Yumura ${ }^{1, *}$ \\ 1 Graduate School of Sciences and Technology for Innovation, Yamaguchi University, \\ Yamaguchi 753-8511, Japan; frog7.atyu-bnai@ezweb.ne.jp (Y.T.); sjahan.biochem@ru.ac.bd (M.G.S.J.); \\ tomokondo@bio.c.u-tokyo.ac.jp (T.K.); i023vc@yamaguchi-u.ac.jp (M.N.) \\ 2 Department of Biochemistry and Molecular Biology, Faculty of Science, University of Rajshahi, \\ Rajshahi 6205, Bangladesh \\ 3 Department of Life Sciences, Graduate School of Arts and Sciences, The University of Tokyo, \\ Tokyo 153-8902, Japan \\ * Correspondence: yumura@yamaguchi-u.ac.jp; Tel.: +81-83-933-5717
}

Received: 17 April 2019; Accepted: 15 May 2019; Published: 17 May 2019

\begin{abstract}
Cytokinesis D is known as the midwife mechanism in which neighboring cells facilitate cell division by crossing the cleavage furrow of dividing cells. Cytokinesis D is thought to be mediated by chemotaxis, where midwife cells migrate toward dividing cells by sensing an unknown chemoattractant secreted from the cleavage furrow. In this study, to validate this chemotaxis model, we aspirated the fluid from the vicinity of the cleavage furrow of a dividing Dictyostelium cell and discharged it onto a neighboring cell using a microcapillary. However, the neighboring cells did not show any chemotaxis toward the fluid. In addition, the cells did not manifest an increase in the levels of intracellular $\mathrm{Ca}^{2+}$, cAMP, or cGMP, which are expected to rise in chemotaxing cells. From several lines of our experiments, including these findings, we concluded that chemotaxis does not contribute to cytokinesis D. As an alternative, we propose a cortical-flow model, where a migrating cell attaches to a dividing cell by chance and is guided toward the furrow by the cortical flow on the dividing cell, and then physically assists the separation of the daughter cells.
\end{abstract}

Keywords: chemotaxis; cortical flow; cytokinesis; Dictyostelium; midwife

\section{Introduction}

Cytokinesis is the final step of cell division. Dictyostelium cells have four modes of cytokinesiscytokinesis A, B, C, and D [1] —although recent studies revised this categorization [2]. Cytokinesis D was observed for the first time in Amoebozoa, Entamoeba invadens [3]. In that study, neighboring cells migrated toward dividing cells and cut the connection between two daughter cells. When the fluid from the vicinity of the cleavage furrow of a dividing Entamoeba cell was aspirated with a micropipette, and then discharged onto distant cells, 37\% of the observed cells extended a directed pseudopod and followed a retracting pipette [3]. Therefore, Biron et al. [3] proposed that the neighboring cells are guided by a chemoattractant secreted by dividing cells and facilitate cytokinesis as a midwife. Additionally, in Dictyostelium cells, neighboring cells often migrate toward dividing cells and cross the cleavage furrow [4,5]. Nagasaki and Uyeda [6] have observed that the green fluorescent protein (GFP)-tagged pleckstrin homology (PH) domain localizes at the leading edge of midwife cells migrating toward the dividing cell. Since the GFP-PH domain localizes at the leading edge of chemotaxing cells in the aggregation stage of this organism, the authors assumed that midwife cells migrate toward the dividing cell because the midwife cells sense the chemoattractant secreted by the dividing cell. 
They refer to it as cytokinesis D to distinguish this phenomenon from the other cytokinesis modes [1]. Entamoeba and Dictyostelium are phylogenetically widely separated. Thus, cytokinesis D may be common among diverse groups of animal and amoeboid cells. Nonetheless, the chemoattractant and signal mechanism, including its receptor, remain unknown.

In this study, we reassessed the chemotaxis model for cytokinesis D. According to the findings made in this study, we concluded that midwife cells do not migrate chemotactically. We propose a novel model, namely, a cortical-flow model, in which migrating cells accidentally attach to dividing cells. They are guided toward the furrow by the cortical flow on the dividing cell and then cross the cleavage furrow, which facilitates the separation of daughter cells.

\section{Materials and Methods}

\subsection{Cell Culture}

Dictyostelium discoideum cells (AX2) were cultured in plastic dishes at $22{ }^{\circ} \mathrm{C}$ in the HL5 medium ( $1.3 \%$ of bacteriological peptone, $0.75 \%$ of yeast extract, $85.5 \mathrm{mM}$ D-glucose, $3.5 \mathrm{mM} \mathrm{Na}_{2} \mathrm{HPO}_{4} \cdot 12 \mathrm{H}_{2} \mathrm{O}_{\text {, }}$ and $3.5 \mathrm{mM} \mathrm{KH} 2 \mathrm{PO}_{4}, \mathrm{pH}$ 6.3), as described previously [7]. The cells were transformed with extrachromosomal vectors for the expression of the GFP-PH domain, GFP-lifeact, Flamindo2, Dd-GCaMP6s, or Dd-Green cGull by electroporation or laser-poration, as described elsewhere [8,9]. Dd-Green cGull served as a cGMP i probe, in which the codon usage of the original Green cGull [10] was optimized for Dictyostelium. The transformed cells were selected in the HL5 medium supplemented with $10 \mu \mathrm{g} / \mathrm{mL}$ G418 (Wako, Osaka, Japan). To observe cytokinesis D, cells were incubated in the HL5 medium. To obtain developed cells in the aggregation stage, after the medium was replaced with BSS ( $3 \mathrm{mM} \mathrm{CaCl}_{2}, 10 \mathrm{mM} \mathrm{KCl}, 10 \mathrm{mM} \mathrm{NaCl}, 3 \mathrm{mM} \mathrm{MES}, \mathrm{pH} 6.3$ ), the cells were maintained at $22{ }^{\circ} \mathrm{C}$ after incubation at $10.5^{\circ} \mathrm{C}$ overnight.

\subsection{Microscopy}

Cells were placed in a glass bottom dish and examined under an inverted differential-interference contrast (DIC) microscope or a phase contrast microscope (IX71, Olympus, Tokyo, Japan). The cells expressing the GFP-PH domain, GFP-lifeact, Flamindo2, Dd-GCaMP6s, or Dd-Green cGull were examined under a confocal microscope (LSM510, Zeiss, Oberkochen, Germany) equipped with a 60× objective and an argon laser (with standard filter settings for GFP). Traction force microscopy was conducted as previously described [11]. For interference reflection microscopy (IRM), the excitation filter (555/25 nm for tetramethyl rhodamine, TRITC), the beam splitter (standard four colors), and the emission filter (525/50 nm for GFP) were employed. IRM visualizes the cell-substratum adhesion as dark areas [12]. Time-lapse images were acquired at an interval of 5 or $10 \mathrm{~s}$. To prepare agar-overlaid cells, a 1.5\% agarose block was overlaid on the cells according to a previously published method [13]. Microcapillaries were made from glass tubes (GD-1, Narishige, Tokyo, Japan) by means of a puller (PB-7, Narishige). The microcapillary was set on a micromanipulator (MO-3, S, Tokyo, Japan), which was installed with the inverted microscope. For experiments involving polystyrene beads, carboxylated beads $(0.5,1.0,3.0$, or $6.4 \mu \mathrm{m}$ in diameter, Polysciences, Warrington, PA, USA) were added to the cells in the glass bottom dish. To fix the cells, they were incubated with $2.5 \%$ formalin in BSS for 30 min and washed with BSS more than five times.

\subsection{Microfluidic Experiments}

A flow chamber ( $\mu$-Slide I Luer, channel volume $150 \mu$ l, Ibidi, Munchen, Germany) was connected with a reservoir containing the HL5 medium and a peristaltic pump. The shear stress was set to $0.06 \mathrm{dyn} / \mathrm{cm}^{2}$, which did not affect cell migration. In chemotaxis experiments, BSS was used in place of the HL5 medium. 


\subsection{Image Analysis}

The acquired images were analyzed in the ImageJ software (http://rsbweb.nih.gov/ij/). For cell tracking, a plugin allowing for "manual tracking" in the Image software was used. Cell velocity was calculated from the centroid after the cell outline was obtained. Time course data on the fluorescence intensities of Flamindo2, Dd-GCaMP6s, and Dd-Green cGull in chemotactic and midwife cells were analyzed with the same software.

To normalize the cell division stages, the mitosis stage index (MSI) was used, as previously described [11]. The MSI was calculated from the long axis (L) and short axis (l) of the cell. The short axis represents the width of the cleavage furrow. The MSI is calculated using the following formula.

$$
\mathrm{MSI}=(\mathrm{L}-1) / \mathrm{L}
$$

When the MSI is 0 , the cell shape is round. When the MSI is 1.0, cell division is complete. The duration of cytokinesis (cytokinesis time) was defined as the time from the initiation of furrowing to the final separation. Graphs were created in GraphPad Prism 7 (GraphPad Software Inc., San Diego, CA, USA) on the basis of the calculations performed in Microsoft Excel.

\subsection{Statistical Analysis}

Statistical analysis was performed using the GraphPad Prism 7. Data are presented as the mean \pm standard deviation (SD) and were analyzed by a Student's $t$ test for a comparison between two groups or by one-way ANOVA with Tukey's multiple-comparison test.

\section{Results and Discussion}

\subsection{Neighboring Cells Facilitate Cell Division}

When Dictyostelium cells enter the mitotic phase, they cease migration, assume a round shape, elongate, and constrict the cleavage furrow to separate into two daughter cells. Neighboring cells often migrate toward dividing cells and cross the cleavage furrow. Figure 1A shows a representative time-lapse image of cytokinesis D (Supplementary Movie 1). The cells were mildly compressed under the agar overlay to improve the image quality. Figure 1B shows a schema of cytokinesis D. Frequencies of cytokinesis D depend on the cell density and were found to be $4.12 \% \pm 0.95 \%$ at a cell density of approximately 1,500 cells $/ \mathrm{mm}^{2}, 2.79 \% \pm 0.69 \%$ at a cell density of $\sim 750$ cells $/ \mathrm{mm}^{2}$, and $1.78 \% \pm 0.76 \%$ at a cell density of $\sim 300$ cells $/ \mathrm{mm}^{2}$ ( $\mathrm{n} \geq 1500$ dividing cells in each of the three experiments).

If the neighboring cells facilitate cytokinesis as midwife cells, then the time required for cytokinesis must be reduced by this process. Figure $1 \mathrm{C}$ shows that cytokinesis time was significantly reduced by midwife cells $(183 \pm 32 \mathrm{~s}$ [mean \pm SD] during normal cell division, $143 \pm 27 \mathrm{~s}$ with midwife cells, $\mathrm{n}=105$ and 57, respectively). Figure 1D shows representative time course data from phase contrast microscopy (Phase) and IRM of dividing cells without (Normal) cells and with midwife cells (Midwife), respectively. The IRM visualizes cell-substratum adhesions as dark areas. In all cases ( $n=40$ cells), the midwife cells penetrated the narrow space between the cleavage furrow and the substratum. Presumably, this penetration by the midwife cell physically facilitates the separation of the daughter cells. 
A

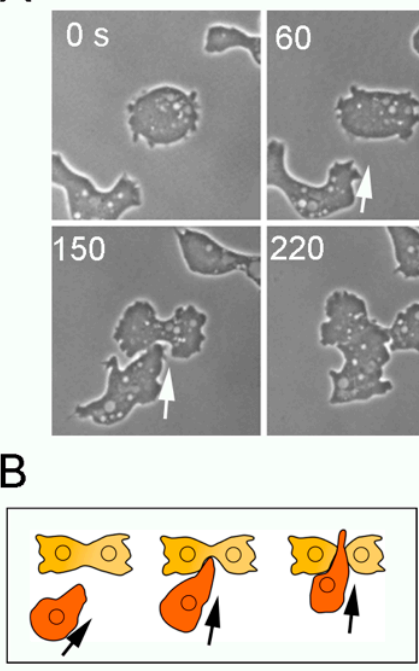

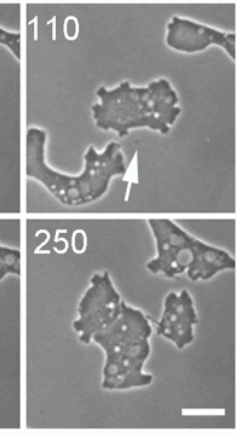

C

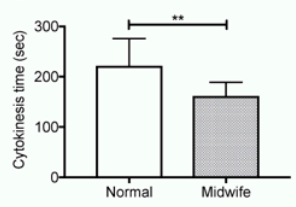

D

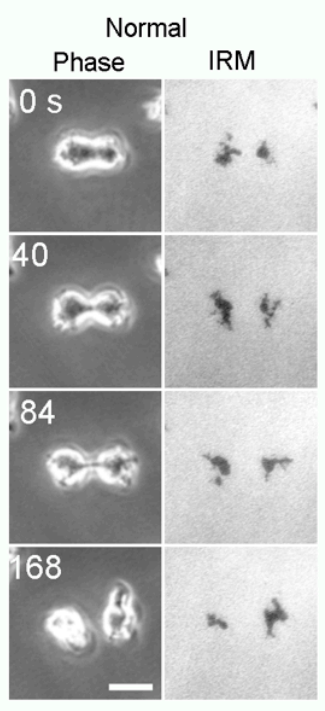

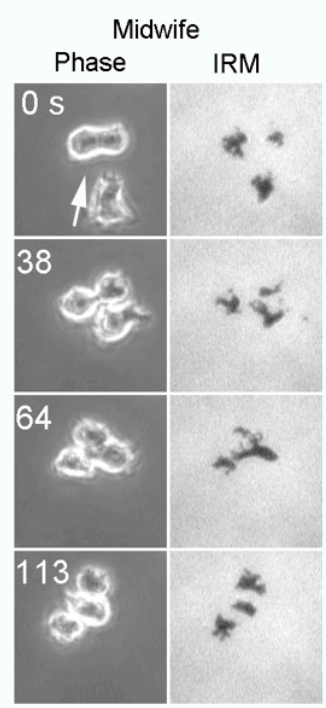

Figure 1. Cytokinesis D depends on migrating neighboring "midwife" cells. (A) A representative time course of cytokinesis D according to phase contrast microscopy. The cells were mildly compressed under an agar overlay to improve the image quality. A neighboring cell migrated toward the dividing cell (arrows) and crossed the cleavage furrow. (B) A schema to explain cytokinesis D. (C) The period from the onset of furrowing to final separation (cytokinesis time) with and without midwife cells. Cells were examined without the agar overlay. Data are presented as the mean $\pm \operatorname{SD}\left(n>45,{ }^{* *} P \leq 0.0001\right.$, paired $t$ test). (D) Representative time course data from phase contrast microscopy and IRM of dividing cells without (Normal) cells and with midwife cells (Midwife), respectively. A neighboring cell (arrow) migrated toward a dividing cell and crossed the narrow space between the cleavage furrow and the substratum. Bars, $10 \mu \mathrm{m}$.

\subsection{Verification of the Chemotaxis Model (1)}

According to the chemotaxis model, an unknown chemotactic substance is secreted from the cleavage furrow of a dividing cell, and neighboring cells migrate toward the furrow because they sense the substance. Biron et al. [3] aspirated fluid from the vicinity of the cleavage furrow of a dividing Entamoeba cell with a micropipette and discharged it in the proximity of a distant cell. They reported that $37 \%$ of the examined cells showed extension of directed pseudopods and followed a retracting pipette.

In the present study, similar experiments were conducted on Dictyostelium cells. Figure 2A depicts a representative experiment. After fluid from the vicinity of the cleavage furrow of a dividing cell was aspirated with a micropipette (upper images in Figure 2A) and discharged near the interphase cells (lower images in Figure 2A), the interphase cells neither extended a directed pseudopod nor followed the micropipette. We obtained the same results in multiple experiments $(n=51)$. As a control, when cAMP, which is a chemoattractant for developed Dictyostelium cells, was applied to the developed cells, they migrated toward the micropipette (Figure 2B). Incidentally, we applied folic acid, which is a chemoattractant for vegetative cells, to vegetative AX2 cells, but the axenic AX2 strain used in this study showed little or no response. This result is consistent with another report [14]. Therefore, we applied cAMP to developed cells as a control.

Nagasaki and Uyeda [6] have provided support to the chemotaxis model in relation to Dictyostelium cells adducing that the GFP-pleckstrin homology $(\mathrm{PH})$ domain of protein kinase $\mathrm{B}$, which is a marker of phosphatidylinositol $(3,4,5)$ trisphosphate, localizes at the leading edge of midwife cells migrating toward a dividing cell. Because the GFP-PH domain localizes at the leading edge of a chemotaxing cell [15], these authors concluded that midwife cells chemotactically migrate toward the dividing cell. In the present study, we confirmed that the GFP-PH domain localizes at the leading edge of midwife cells (arrowheads in Figure 2C, Supplementary Movie 2). Nevertheless, the GFP-PH domain also 
localized at the leading edge of migrating non-midwife cells in the absence of chemotaxis (Figure 2D), which is in agreement with more recent observations [14].

A

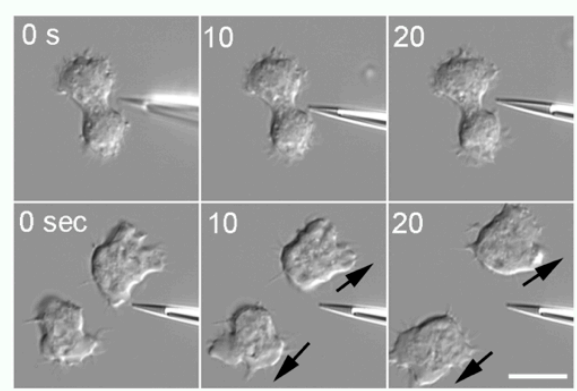

B

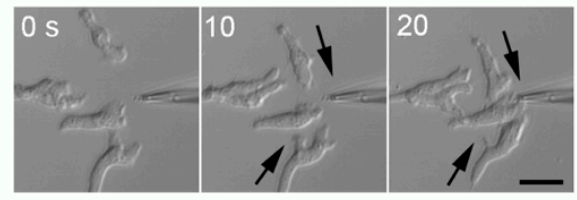

C

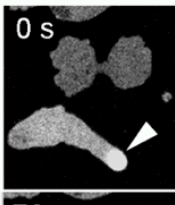
30

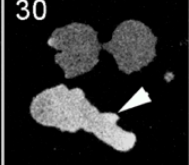

60

70

90

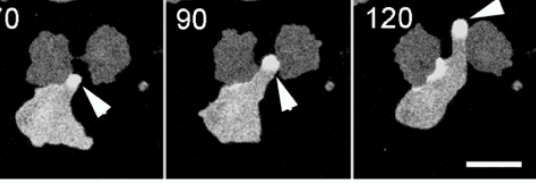

D
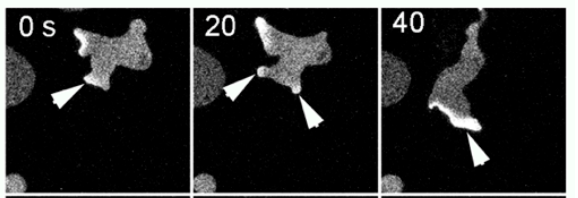

60
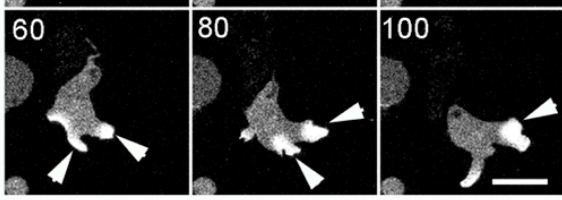

Figure 2. Midwife cells do not respond to the fluid collected near a dividing cell. (A) When fluid from the vicinity of the cleavage furrow of a dividing cell was aspirated with a micropipette (upper panels) and discharged near interphase cells (lower panels), the interphase cells neither extended a directed pseudopod nor followed the micropipette $(n=51)$. (B) As a control, when a micropipette containing $10 \mu \mathrm{M}$ cAMP was applied to developed cells, they migrated toward the micropipette. (C) The GFP-PH domain (arrowheads) localized at the leading edge of migrating midwife cells toward a dividing cell. (D) The GFP-PH domain (arrowheads) localized at the leading edge of freely migrating vegetative cells. Bars, $10 \mu \mathrm{m}$.

Nagasaki and Uyeda [6] have reported that mutant cells deficient in the G protein $\beta$ subunit, which mediates Dictyostelium chemotaxis via surface receptors, show a lower frequency of cytokinesis $\mathrm{D}$ than wild-type cells. We can explain this finding as follows. Most mutant cells cannot encounter dividing cells in time because the average velocity of mutant cells $(1.96 \pm 0.57 \mu \mathrm{m} / \mathrm{min}, \mathrm{n}=60)$ is much lower than that of wild-type cells $(5.67 \pm 1.28 \mu \mathrm{m} / \mathrm{min}, \mathrm{n}=60)$.

\subsection{Verification of the Chemotaxis Model (2)}

The above micropipette experiments indicate that midwife cells do not migrate chemotactically. However, it is possible that the concentration of the putative unknown chemotactic substance is not sufficient to attract cells in the micropipette experiments. Therefore, we next examined the intracellular concentrations of cAMP $\left(\mathrm{cAMP}_{\mathrm{i}}\right), \mathrm{Ca}$ ions $\left(\mathrm{Ca}_{\mathrm{i}}{ }^{2+}\right)$, and cGMP $\left(\mathrm{cGMP}_{\mathrm{i}}\right)$ in midwife cells. It is known that when cAMP, which is a chemoattractant for Dictyostelium, is applied to developed cells, the levels of $\mathrm{cAMP}_{\mathrm{i}}, \mathrm{Ca}_{\mathrm{i}}{ }^{2+}$, and $\mathrm{cGMP}_{\mathrm{i}}$ transiently increase under the action of cell surface receptors [16-19]. To test whether the levels of $\mathrm{cAMP}_{\mathrm{i}}, \mathrm{Ca}_{\mathrm{i}}{ }^{2+}$, and $\mathrm{cGMP}_{\mathrm{i}}$ increase in midwife cells, a cAMP sensor (Flamindo2), a $\mathrm{Ca}_{\mathrm{i}}{ }^{2+}$ sensor (Dd-GCaMP6s), and a cGMP sensor (Dd-Green cGull) were expressed in the cells, respectively.

When cAMP was applied as a control to the developed cells, cAMP $_{\mathrm{i}}$ transiently increased because the fluorescence due to Flamindo2 transiently decreased (Figure 3A, Flamindo2, Chemotaxis). However, midwife cells did not show any notable increase in $\mathrm{CAMP}_{\mathrm{i}}$ concentration (Figure 3A, Flamindo2, Midwife, Supplementary Movie 3). Additionally, $\mathrm{Ca}_{\mathrm{i}}{ }^{2+}$ levels transiently increased (Figure 3A, GCaMP, Chemotaxis). However, midwife cells did not show any increase in $\mathrm{Ca}_{\mathrm{i}}{ }^{2+}$ concentration (Figure 3A, 


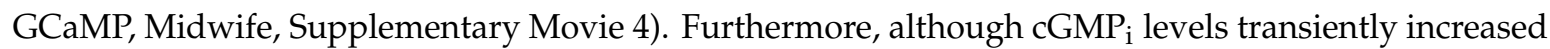
(Figure 3A, cGull, Chemotaxis), midwife cells did not show any increase in cGMP ${ }_{\mathrm{i}}$ concentration (Figure 3A, cGull, Midwife, Supplementary Movie 5).

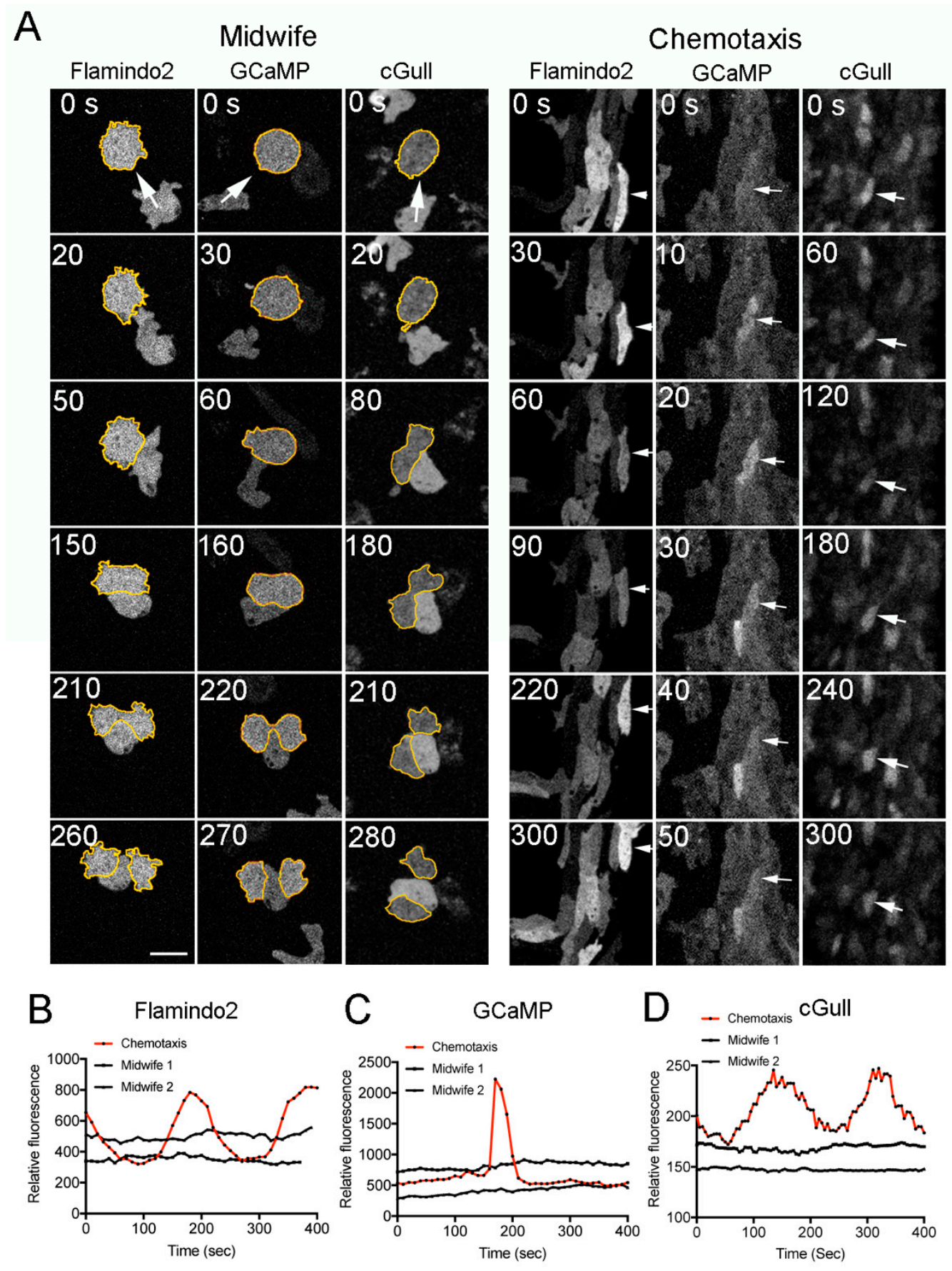

Figure 3. There are no notable changes in $\mathrm{Ca}_{\mathrm{i}}{ }^{2+}, \mathrm{cAMP}_{\mathrm{i}}$, and cGMPi levels in midwife cells. To examine $\mathrm{Ca}_{\mathrm{i}}{ }^{2+}, \mathrm{cAMP}_{\mathrm{i}}$, and $\mathrm{CGMP}_{\mathrm{i}}$ in midwife cells, Flamindo2, Dd-GCaMP6s, and Dd-Green cGull were expressed in the cells, respectively. (A) Midwife cells did not show any notable changes in $\mathrm{CAMP}_{\mathrm{i}}, \mathrm{Ca}_{\mathrm{i}}{ }^{2+}$ and $\mathrm{CGMP}_{\mathrm{i}}$ levels. Dividing cells are outlined in yellow. As a control, in a cell aggregation stream, the developed cells showed a transient increase in $\mathrm{CAMP}_{\mathrm{i}}, \mathrm{Ca}_{\mathrm{i}}{ }^{2+}$, and $\mathrm{CGMP}_{\mathrm{i}}$ concentrations (arrows in each panel). Bar, $10 \mu \mathrm{m}$. (B-D) Representative time course data on $\mathrm{CAMP}_{\mathrm{i}}, \mathrm{Ca}_{\mathrm{i}}{ }^{2+}$, and $\mathrm{CGMP}_{\mathrm{i}}$ in midwife cells (two examples in each graph, black) and a chemotactically developed cell (red), respectively. 
Figure 3B-D show representative time course data on each reaction of $\mathrm{CAMP}_{\mathrm{i}}, \mathrm{Ca}_{\mathrm{i}}{ }^{2+}$, and $\mathrm{CGMP}_{\mathrm{i}}$ in chemotactic (red) and midwife (black) cells, respectively. Incidentally, the dividing cells did not show any increases in $\mathrm{CAMP}_{\mathrm{i}}, \mathrm{Ca}_{\mathrm{i}}{ }^{2+}$, and $\mathrm{cGMP}_{\mathrm{i}}$ levels either. Similar results were confirmed in multiple cells $(n>30)$ in each case.

Collectively, these data mean that the midwife cells do not undergo any changes in the levels of $\mathrm{CAMP}_{\mathrm{i}}, \mathrm{Ca}_{\mathrm{i}}{ }^{2+}$, or $\mathrm{CGMP}_{\mathrm{i}}$, which suggests that they do not migrate chemotactically toward the dividing cells. On the other hand, the putative chemotactic substance may not necessarily affect $\mathrm{cAMP}_{\mathrm{i}}, \mathrm{Ca}_{\mathrm{i}}{ }^{2+}$, and $\mathrm{CGMP}_{\mathrm{i}}$.

\subsection{Verification of the Chemotaxis Model (3)}

Next, cytokinesis D was examined in a microfluidic chamber. If the medium constantly flows in one direction, the hypothetical unknown substance secreted by dividing cells will flow away and, therefore, only the midwife cells down the stream will migrate toward the dividing cell (Figure 4A). It is known that cells can migrate against shear flow [20,21]. To prevent this reaction, we first optimized the flow rate and set the shear stress to $0.06 \mathrm{dyn} / \mathrm{cm}^{2}$. Figure $4 \mathrm{~B}$ illustrates the results of tracking migrating cells without flow (upper panel) and with flow (lower panel). The optimized flow rate did not affect cell migration ( $\mathrm{n}=60$ cells, each).
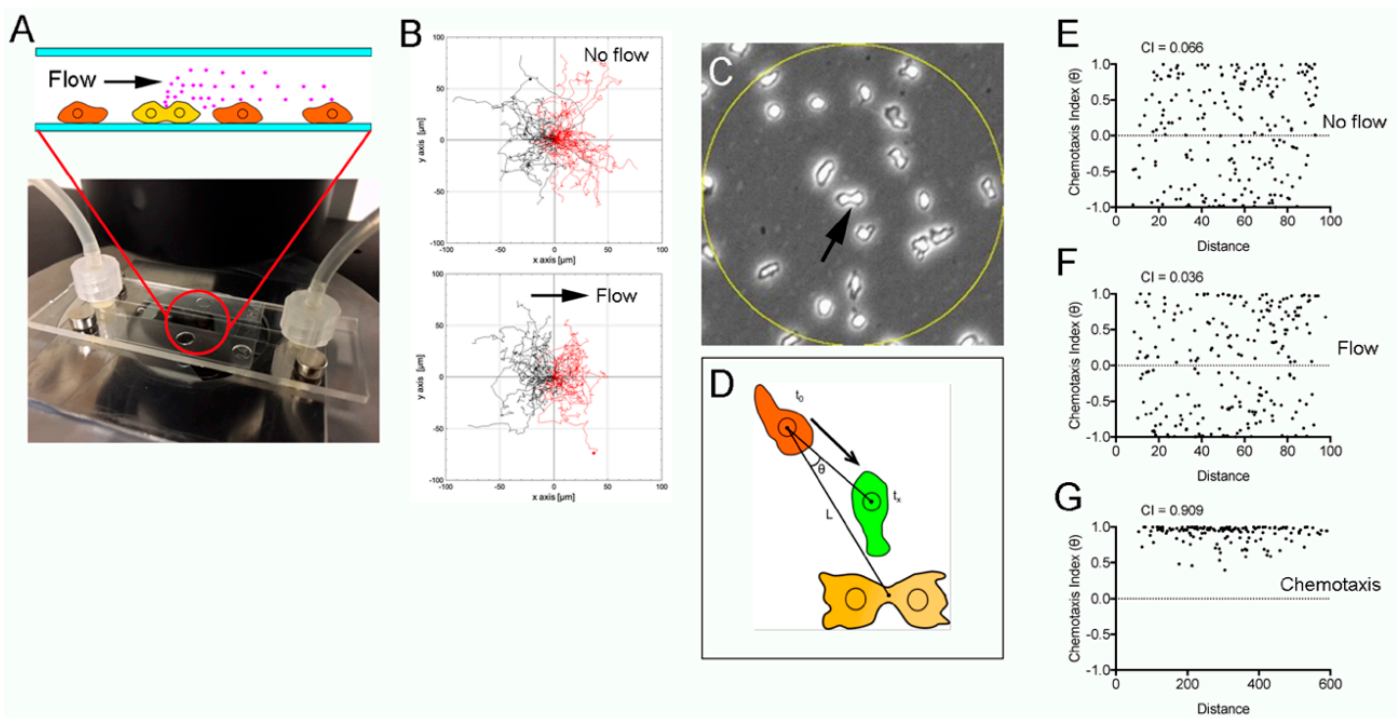

Figure 4. Midwife cells do not migrate toward a dividing cell chemotactically. (A) Cytokinesis D was examined in a microfluidic chamber with constant flow. If the medium constantly flows in one direction, a hypothetical unknown substance (red particles) secreted by dividing cells goes with the flow, and midwife cells migrate toward the dividing cell only from downstream locations. (B) Tracking of freely migrating cells without flow (upper panel) and with flow (lower panel). Note that the optimized flow did not affect cell migration. (C) In the flow chamber, the CI was examined within the circle with a 100- $\mu \mathrm{m}$ diameter (yellow circle) when the dividing cell was located at its center (arrow). (D) The CI was defined as the cosine of the angle consisting of three points: the initial position (red), the position of the furrow of the dividing cell (yellow), and the displaced position (green) after 3 min of cell migration. (E) Plots of the CI versus the distance of a cell from the dividing cell in the absence of flow ( $\mathrm{n}=212$ cells, three independent experiments). (F) Plots of the CI versus the distance of a cell from the dividing cell in the presence of flow ( $n=215$ cells, three independent experiments). (G) Plots of the CI versus the distance of a cell from the aggregation center $(n=157)$. In this case, the CI was calculated from the angle involving the aggregation center in place of the position of the dividing cell.

Next, the chemotaxis index $(\mathrm{CI})$ was compared between the upstream and downstream locations within a circle with a 100- $\mu \mathrm{m}$ diameter (yellow circle), while a dividing cell was located at the center of the circle (Figure $4 \mathrm{C}$ ). In this case, the $\mathrm{CI}$ was defined as the cosine of the angle consisting of the 
following three points: the initial position (red), the position of the furrow of a dividing cell (yellow), and the displaced position (green) after 3 minutes of cell migration (Figure 4D). If the cell migrates straight toward the dividing cell, then the CI takes the value of 1.0, and if the cell recedes straight away, then the $\mathrm{CI}$ is -1.0 . Figure $4 \mathrm{E}, \mathrm{F}$ show plots of the $\mathrm{CI}$ versus the distance of a cell from the dividing cell with and without flow ( $\mathrm{n}=212$ and 215 cells, three independent experiments). There was no significant difference between the average CI without flow (0.066) and with flow (0.036). In the control, when developed cells chemotactically migrated toward the aggregation center, the average CI was 0.909 $(n=157)$ and was calculated from the angle involving the aggregation center in place of the position of the dividing cell (Figure $4 \mathrm{G}$ ).

Collectively, these findings reveal that neighboring cells are not directed by dividing cells. Thus, we concluded that midwife cells are not affected by chemotaxis toward the dividing cells.

\subsection{The Cortical-Flow Model}

When a migrating cell attaches to a dividing cell, the following three events are observed (Figure 5A). (1) The cell migrates along the surface of the dividing cell toward the cleavage furrow. (2) The cell migrates along the surface of the dividing cell toward the pole. (3) The cell departs from the dividing cell. Figure $5 \mathrm{~B}$ presents the frequencies of these three events. Of note, the cells more frequently migrated along the surface of the dividing cell toward its cleavage furrow $(70 \pm 8 \%, n=186)$.

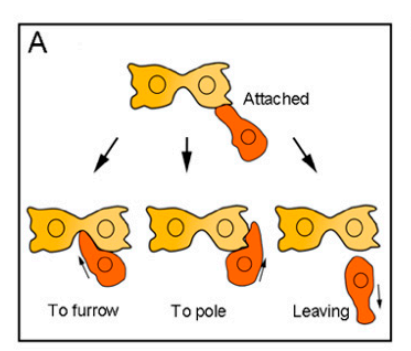

B

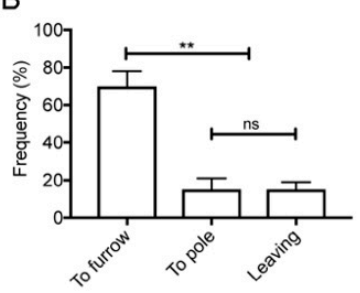

C

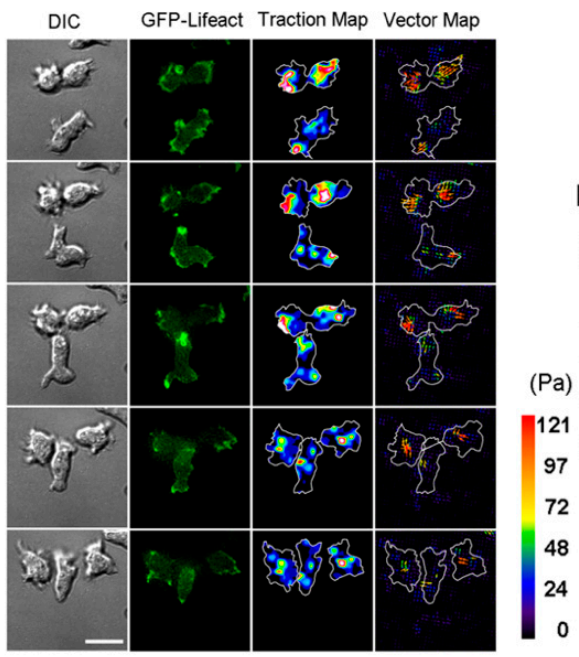

D

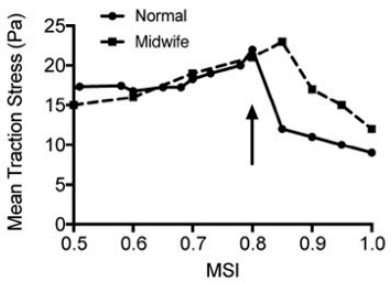

Figure 5. Cell behavior and traction force during cytokinesis D. (A) When a migrating cell attaches to a dividing cell, three behaviors were observed. (1) The cell migrates along the surface of the dividing cell toward the cleavage furrow. (2) The cell migrates along the surface of the dividing cell toward the pole. (3) The cell departs from the dividing cell. (B) Frequencies of three events. Data are presented as the mean $\pm \mathrm{SD}$ ( $\mathrm{n}=62,43$, and 32, three experiments). ${ }^{* *} P \leq 0.0001$, ns: not significant, $P>0.05$. (C) A typical DIC image, a fluorescence image of GFP-lifeact (a marker of actin filaments), a traction map, and the traction vector map during cytokinesis $\mathrm{D}$. The color code indicates the magnitude of traction stress. Bar, $10 \mu \mathrm{m}$. (D) Representative time course data on the mean traction stress of a dividing cell with (Normal) and without midwife cells (Midwife). To normalize the cell division stages, the mitosis stage index (MSI) was employed as described in Materials and Methods. The arrow indicates the timing when the midwife cell passed through the cleavage furrow of a dividing cell.

Midwife cells may exert force to separate the daughter cells. The traction force was examined during cytokinesis D by traction force microscopy [11]. Figure 5C shows a representative DIC image, a fluorescence image of GFP-lifeact (a marker of actin filaments), a traction map, and a vector map during cytokinesis D. The traction force of the dividing cell was exerted toward the furrow from both daughter cells. When the midwife cell passed under the cleavage furrow, the traction force of dividing 
cells significantly diminished (the arrow in Figure 5D), which indicates that the insertional migration of the midwife cell cut the connection between daughter cells. This results in the relaxation of the traction force of the dividing cell.

It has been previously known that the cortical actin cytoskeleton flows toward the cleavage furrow in dividing cells $[7,22]$. As an alternative model of cytokinesis $\mathrm{D}$, we hypothesized the following: a neighboring cell freely migrates, attaches to a dividing cell by chance, and is guided toward the cleavage furrow by the cortical flow. To assess this cortical-flow model, carboxylated polystyrene beads of various sizes were attached to the surface of dividing cells. The attached beads always moved toward the cleavage furrow (Figure 6A, Supplementary Movie 6). Next, chemically fixed cells (i.e., dead cells) were attached to the surface of the dividing cells. These cells also moved toward the cleavage furrow (Figure 6A, Supplementary Movie 7).

A
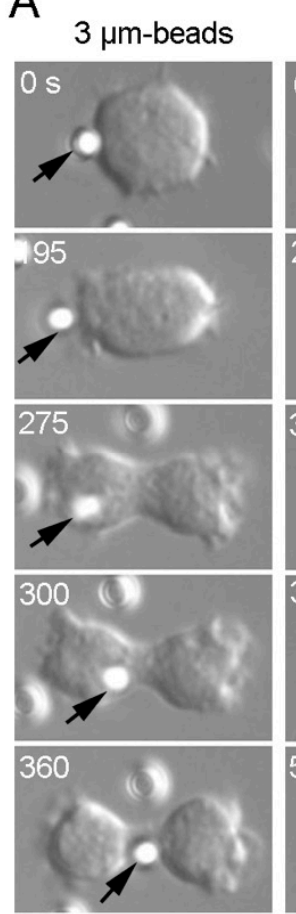

$6.4 \mu \mathrm{m}$-beads
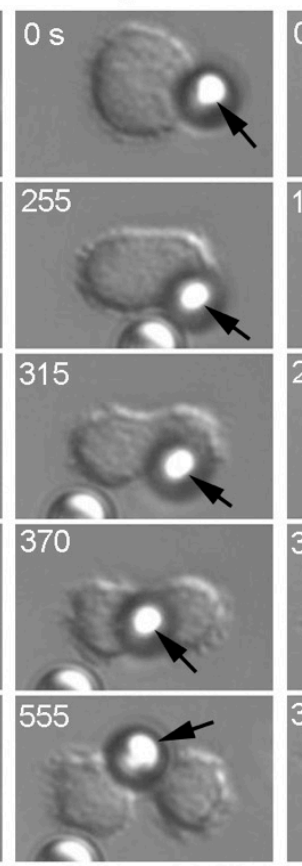

Fixed cells

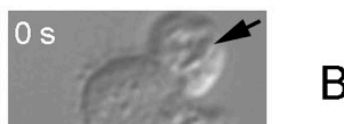

B

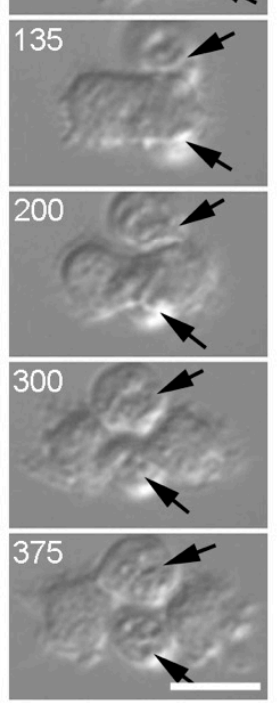

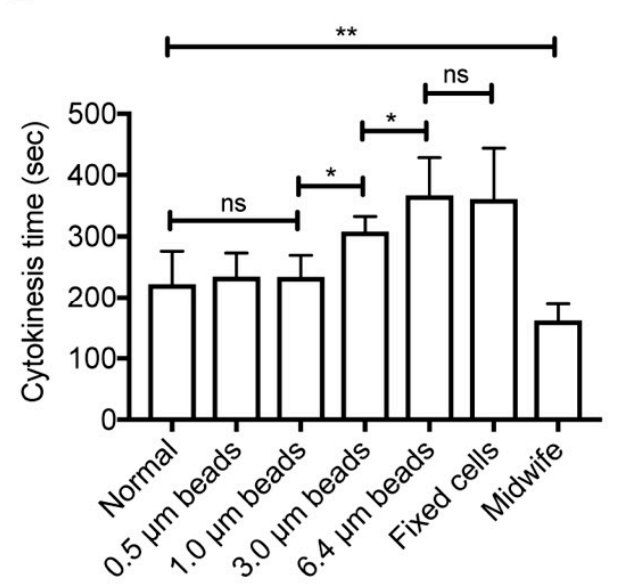

Figure 6. The cortical flow of attached beads. (A) Representative time course data on the movement of beads ( $3 \mu \mathrm{m}$ and $6.4 \mu \mathrm{m}$ in diameter) and fixed cells attaching to dividing cells. Note that the beads and the fixed cells (arrows) move toward the cleavage furrow. Bar, $10 \mu \mathrm{m}$. (B) Cytokinesis time when the beads or fixed cells were attached to dividing cells. Data are presented as mean \pm SD ( $n>40$, three experiments). ${ }^{*} P \leq 0.001$. ${ }^{* *} P \leq 0.0001$. ns: not significant, $P>0.05$.

To evaluate the efficiency of cytokinesis with attached beads or fixed cells, cytokinesis time was examined in each case (Figure 6B). Both larger beads and fixed cells increased cytokinesis time. Because smaller beads $(0.5$ and $1 \mu \mathrm{m})$ did not affect cytokinesis time, the observed retardation may be due to their heavy load. Since cytokinesis time was significantly shorter in cytokinesis D with live cells (Midwife in Figure 6B), live cells are, therefore, required for efficient cytokinesis D.

For the cortical-flow model, cell-cell adhesion is essential. Cytokinesis D was not observed in cells with a deficiency of a cell-cell adhesion molecule (csB-null cells, data not shown). However, most of those cells were found to be detached from the substratum because this molecule is also related to cell-substratum adhesion. Therefore, we could not validate this model by the current experiments. In the future, we must conduct experiments on other mutants deficient in cell-cell adhesion molecules.

As another plausible model, asymmetric distribution (therefore, a gradient) of surface molecules of the dividing cells may guide the directional migration of a midwife cell using a haptotaxis mechanism. 
Nonetheless, the cortical-flow model is more likely than this model because the beads also moved toward the cleavage furrow.

Consequently, we concluded that the midwife mechanism is explained by the cortical-flow model but not by the chemotaxis model.

Supplementary Materials: The Supplementary Materials are available online http://www.mdpi.com/2073-4409/8/ 5/473/s1.

Author Contributions: Conceptualization, S.Y. Methodology, S.Y. Validation, S.Y. Formal analysis, Y.T. and S.Y. Investigation, Y.T., M.G.S.J., N.M., and T.K. Writing-original draft preparation, Y.T., M.G.S.J., T.K., M.N., and S.Y. Writing - review and editing, T.Y., M.G.S.J., T.K., M.N., and S.Y. Visualization, S.Y.

Funding: This research did not receive any specific grant from funding agencies in the public, commercial, or not-for-profit sectors.

Acknowledgments: We are grateful to the members of the Dictyostelium research community, the Dicty Stock Center, and the NBRP Nenkin for providing some of the mutants that were used in this study. We thank A. Nagasaki and T. Kitanishi-Yumura for their helpful comments.

Conflicts of Interest: The authors declare no conflict of interest.

\section{References}

1. Uyeda, T.Q.; Nagasaki, A. Variations on a theme: The many modes of cytokinesis. Curr. Opin. Cell Biol. 2004, 16, 55-60. [CrossRef]

2. Taira, R.; Yumura, S. A novel mode of cytokinesis without cell-substratum adhesion. Sci. Rep. 2017, 7, 17694. [CrossRef] [PubMed]

3. Biron, D.; Libros, P.; Sagi, D.; Mirelman, D.; Moses, E. Asexual reproduction: 'Midwives' assist dividing amoebae. Nature 2001, 410, 430. [CrossRef]

4. Insall, R.; Müller-Taubenberger, A.; Machesky, L.; Köhler, J.; Simmeth, E.; Atkinson, S.J.; Weber, I.; Gerisch, G. Dynamics of the Dictyostelium Arp2/3 complex in endocytosis, cytokinesis, and chemotaxis. Cell Motil. Cytoskelet. 2001, 50, 115-128. [CrossRef] [PubMed]

5. Rohlfs, M.; Arasada, R.; Batsios, P.; Janzen, J.; Schleicher, M. The Ste20-like kinase SvkA of Dictyostelium discoideum is essential for late stages of cytokinesis. J. Cell Sci. 2007, 120, 4345-4354. [CrossRef]

6. Nagasaki, A.; Uyeda, T.Q. Chemotaxis-mediated scission contributes to efficient cytokinesis in Dictyostelium. Cell Motil. Cytoskelet. 2008, 65, 896-903. [CrossRef]

7. Yumura, S. Myosin II dynamics and cortical flow during contractile ring formation in Dictyostelium cells. J. Cell Biol. 2001, 154, 137-146. [CrossRef]

8. Yumura, S.; Matsuzaki, R.; Kitanishi-Yumura, T. Introduction of macromolecules into living Dictyostelium cells by electroporation. Cell Struct. Funct. 1995, 20, 185-190. [CrossRef]

9. Yumura, S. A novel low-power laser-mediated transfer of foreign molecules into cells. Sci. Rep. 2016, 6, 22055. [CrossRef]

10. Matsuda, S.; Harada, K.; Ito, M.; Takizawa, M.; Wongso, D.; Tsuboi, T.; Kitaguchi, T. Generation of a cGMP indicator with an expanded dynamic range by optimization of amino acid linkers between a fluorescent protein and PDE5 $\alpha$. ACS Sens. 2017, 2, 46-51. [CrossRef] [PubMed]

11. Jahan, M.G.S.; Yumura, S. Traction force and its regulation during cytokinesis in Dictyostelium cells. Eur. J. Cell Biol. 2017, 96, 515-528. [CrossRef] [PubMed]

12. Uchida, K.S.; Yumura, S. Dynamics of novel feet of Dictyostelium cells during migration. J. Cell Sci. 2004, 117, 1443-1455. [CrossRef] [PubMed]

13. Yumura, S.; Itoh, G.; Kikuta, Y.; Kikuchi, T.; Kitanishi-Yumura, T.; Tsujioka, M. Cell-scale dynamic recycling and cortical flow of the actin-myosin cytoskeleton for rapid cell migration. Biol. Open 2013, 2, 200-209. [CrossRef]

14. Veltman, D.M.; Lemieux, M.G.; Knecht, D.A.; Insall, R.H. PIP3-dependent macropinocytosis is incompatible with chemotaxis. J. Cell Biol. 2014, 204, 497-505. [CrossRef] [PubMed]

15. Parent, C.A.; Devreotes, P.N. A cell's sense of direction. Science 1999, 284, 765-770. [CrossRef]

16. Bagorda, A.; Das, S.; Rericha, E.C.; Chen, D.; Davidson, J.; Parent, C.A. Real-time measurements of cAMP production in live Dictyostelium cells. J. Cell Sci. 2009, 122, 3907-3914. [CrossRef] [PubMed] 
17. Hashimura, H.; Morimoto, Y.V.; Yasui, M.; Ueda, M. Collective cell migration of Dictyostelium without cAMP oscillations at multicellular stages. Commun. Biol. 2019, 2, 34. [CrossRef] [PubMed]

18. Mato, J.M.; Krens, F.A.; van Haastert, P.J.; Konijn, T.M. 3':5'-cyclic AMP-dependent 3':5'-cyclic GMP accumulation in Dictyostelium discoideum. Proc. Natl. Acad. Sci. USA 1977, 74, 2348-2351. [CrossRef] [PubMed]

19. Yumura, S.; Furuya, K.; Takeuchi, I. Intracellular free calcium responses during chemotaxis of Dictyostelium cells. J. Cell Sci. 1996, 109, 2673-2678.

20. Dalous, J.; Burghardt, E.; Müller-Taubenberger, A.; Bruckert, F.; Gerisch, G.; Bretschneider, T. Reversal of cell polarity and actin-myosin cytoskeleton reorganization under mechanical and chemical stimulation. Biophys. J. 2008, 94, 1063-1074. [CrossRef]

21. Décave, E.; Rieu, D.; Dalous, J.; Fache, S.; Brechet, Y.; Fourcade, B.; Satre, M.; Bruckert, F. Shear flow-induced motility of Dictyostelium discoideum cells on solid substrate. J. Cell Sci. 2003, 116, 4331-4343. [CrossRef] [PubMed]

22. Bray, D.; White, J.G. Cortical flow in animal cells. Science 1988, 239, 883-888. [CrossRef] [PubMed]

(C) 2019 by the authors. Licensee MDPI, Basel, Switzerland. This article is an open access article distributed under the terms and conditions of the Creative Commons Attribution (CC BY) license (http://creativecommons.org/licenses/by/4.0/). 